ISSN $1515-7326, \mathrm{n}^{\circ} 16,1 \mid 2015$, pp. 7 a 13

\title{
Introducción a "Legalismo moral y tolerancia. Crónica de una muerte anunciada" de René González de la vega
}

\author{
Introduction to "Legalismo moral \\ y tolerancia. Crónica de una muerte anunciada" \\ by René González de la vega
}

Adriana Vercellone*

Recepción y evaluación de propuesta: 20/2/2014

Aceptación: 20/03/2014

Recepción y aceptación final: 22/6/2015

Resumen: En el presente número se recoge una discusión sobre el lugar que ocupa la tolerancia en el liberalismo. En coincidencia con esto, la teoría de John Rawls ha significado la posibilidad de conciliar diferentes ideas, bajo un esquema político justo y estable entre los ciudadanos de una comunidad dividida por doctrinas religiosas, filosóficas o morales; la tolerancia será el mecanismo que contribuya a enfrentar los conflictos que se susciten. Sin embargo, asumiendo que el pluralismo subsistirá, el concepto de tolerancia ha jugado un papel central. Esta idea propone discutir René Gonzales de la Vega en "Legalismo moral y tolerancia. Crónica de una muerte anunciada", del cual surge la preocupación de lo que significa la tolerancia para el ciudadano, esto es, el costo que suele representarle.

Palabras Claves: liberalismo, tolerancia, conflictos

* SECyT / Universidad Nacional de Córdoba, Córdoba-Argentina.

E-mail: adrivercellone@gmail.com. 
Adriana Vercellone

\begin{abstract}
In this issue a discussion of the place of tolerance in liberalism is collected. Coinciding with this, the theory of John Rawls has meant the possibility to combine different ideas, under a just and stable political framework between the citizens of a community divided by religious, philosophical and moral doctrines; tolerance is the mechanism to help deal with conflicts that may arise. However, assuming that pluralism stands, the concept of tolerance has played a central role. This idea aims to discuss Rene Gonzales de la Vega in "Moral legalism and tolerance. Chronicle of a death foretold", which concerns what the citizen tolerance arises, that is, the cost that often represents to them.
\end{abstract}

Key Words: liberalism, tolerance, conflict.

Este número de Discusiones recoge el trabajo de cuatro pensadores que proponen reflexionar sobre el lugar que ocupa la tolerancia en el liberalismo.

Bien es sabido que el pluralismo y los desacuerdos constituyen ideas centrales en la teoría liberal. En realidad, son su punto de partida, si los entendemos como un rasgo inevitable de toda sociedad moderna y aquello con lo que debe lidiar cualquier concepción política o moral que pretenda guiar conductas individuales. En coincidencia con esto, uno de los grandes atractivos del liberalismo político de John Rawls ha sido la posibilidad de conciliar diferentes ideas sobre aquello que es recto y justo bajo una concepción razonable de la justicia. De acuerdo a este filósofo, es posible acordar un esquema político justo y estable entre los ciudadanos de una comunidad que se encuentran divididos por doctrinas religiosas, filosóficas o morales aparentemente inconmensurables. El resultado es una concepción de la justicia que, lejos de imponer una visión sobre la moral o la religión, constituye un punto de intersección en el que toda doctrina comprehensiva razonable puede coincidir ${ }^{1}$.

En esta estructura, la tolerancia es el mecanismo que contribuye a enfrentar los conflictos prácticos que se suscitan a raíz de un desacuerdo de principios. Cualquier persona cuyas convicciones personales sean molestadas por conductas o principios de terceros encuentra en la tole-

1 Rawls, J. (1996) Liberalismo politico, trad. SR Madero, FCE, Mexico. 
rancia una razón moral para no intervenir. Asimismo, otros modos de resolver dicha divergencia - por ejemplo, la imposición de un punto de vista por medio de la violencia o la fuerza - entrarían en contradicción con otros principios profundamente arraigados en una comunidad política en la que sus miembros se reconocen como libres e iguales.

Asumiendo que el pluralismo subsistirá, el concepto de tolerancia ha jugado un papel central en la mayoría de los desarrollos contemporáneos de la tesis liberal, y puede decirse que ha acompañado como un móvil la argumentación de Rawls. Esta idea, que para algunos se encuentra en el corazón del liberalismo político, es la que propone discutir René González de la Vega en "Legalismo moral y tolerancia. Crónica de una muerte anunciada", texto que da inicio a esta discusión.

Surge del artículo que una de sus principales preocupaciones radica en lo que la tolerancia significa para el ciudadano, esto es, el costo que suele representarle. En concreto, González cree que la tolerancia puede jugar dos diferentes papeles en las elecciones individuales, ambos problemáticos.

El primero sucede toda vez que las personas estamos en presencia de un conflicto entre valores morales. Es decir, se daría en aquellos casos en los que podemos reconocer que una convicción moral es lesionada por el acto de un tercero, y que también otro valor moral nos invita a tolerar dicha acción. Enfrentados a esta situación, la tolerancia nos empuja a derogar una convicción moral personal que es esencial para nuestra configuración como personas. Es aquí cuando González cree que las dos alternativas disponibles, interferir en la acción del tercero o elegir honrar la propia convicción - y no interferir-, conllevan una consecuencia que no puede ser percibida sino como una pérdida moral personal. Con esto el autor explica una intuición que podemos compartir: cualquiera que haya experimentado esa sensación de molestia o pérdida vacila en afirmar que la tolerancia constituye una virtud, sino una postura recalcitrante.

El segundo de los roles que alude González se presenta cuando entendemos la tolerancia como un mecanismo que enfrenta conflictos entre convicciones morales y principios no morales. Aquí, por razones deontológicas las personas nos inclinamos por priorizar la convic- 
ción moral descartando lo no moral; o bien, aceptamos esta última dentro del espectro de nuestro sistema normativo moral. Si esto es así, entonces la tolerancia se reduce a un procedimiento lógico para jerarquizar, absorber y descartar principios; no es una virtud relevante, sino una actitud irrelevante.

Creo que la intuición que subyace al argumento de González es que una persona puede sentirse asfixiada cuando encuentra que sus propias convicciones son puestas en cuestión; y más aun cuando la tolerancia es el camino de acción sugerido. Porque, como indica, rechazar una convicción personal o inflar el propio sistema de convicciones morales deja un residuo evidentemente perceptible.

Claro que a este autor no se le pasan por alto las ventajas de los principios rawlsianos, y por eso su artículo no presenta en realidad un ataque al liberalismo político ni a la capacidad que este tiene de lidiar con el pluralismo razonable. Por el contrario, su objetivo es señalar una incoherencia entre algunas de las piezas fundamentales de dicha teoría y las exigencias de la tolerancia. Esta aludida incoherencia se entiende mejor cuando describimos al liberalismo rawlsiano tal como González lo reconstruye en su texto: como una tesis deontológica de la moral y la justicia, y a la tolerancia como un ideal. Si bien no pretendemos reproducir aquí todos estos presupuestos y conceptos, vale aclarar dos cosas sobre las conclusiones a las que llega. Primero, elige la versión rawlsiana del liberalismo para discutir, si bien entiende que sus observaciones son extensivas a todo el liberalismo deontológico. Segundo, entiende que el liberalismo político puede dar batalla a las consecuencias prácticas del pluralismo con propias herramientas, prescindiendo de la tolerancia. Por decirlo de otro modo, si usted es un liberal y desea evitar una encerrona moral, González le sugiere abandonar la práctica de la tolerancia para mantener su teoría a salvo.

El primero de los articulistas, Julio Montero, coincide con González en que la tolerancia necesariamente implica un desgarramiento interno en la persona. De alguna manera, permitir la realización de actos que nos parecen desaprobados no puede no dejar residuo. 
No obstante, este autor avanza en rescatar la tolerancia como virtud y situarla en un lugar de privilegio.

Por un lado, apoyándose en la distinción rawlsiana entre vida personal y vida pública, Montero explica que la tolerancia no tiene como efecto la supresión o neutralización de una convicción personal, sino la renuncia a la pretensión de que esta pueda justificar todo el plano político. Es decir que cuando practicamos la tolerancia, la vida personal sigue encontrándose guiada por convicciones éticas personales, aunque no así las decisiones en el ámbito público.

Por otro lado, el autor hace hincapié en que la práctica de dicha actitud es el resultado de un proceso complejo de deliberación que las personas realizan en torno a los propios principios, las creencias ajenas, el contexto y la conducta en cuestión. Y esta es la tarea que nos lleva a concluir si es dable interferir o no. Aun cuando tolerar que otros orienten su vida personal o política de acuerdo a sus propios principios suponga una sensación de pérdida, para Montero lo relevante es el tipo de ejercicio que ha significado en la persona. Por ello es que afirma que la tolerancia requiere de agentes verdaderamente reflexivos, en otras palabras, virtuosos. Así, lo que se encuentra detrás de ese desgarramiento interno o, vale decir, el proceso interno que ha concluido en una sensación de pérdida moral, permite que podamos reconocerle a la tolerancia un lugar privilegiado en el liberalismo rawlsiano.

En la misma línea argumentativa, Fernando Lizárraga emprende la tarea de salvar a John Rawls de las objeciones de González. Para ello nos recuerda que a Rawls le interesan las virtudes institucionales, y no así las personales. Y por ello, cualquier crítica a su teoría situada desde el agente no es eficaz. Al decir esto, el autor cree que el argumento que guía el texto de González, centrado en las consecuencias prácticas de la tolerancia para las personas, es un signo de que ambos coinciden en lo siguiente: que la tolerancia —así como las demás virtudes - no pueden ser solo institucionales sino también personales. Aunque en definitiva, como se señaló, la objeción de González no podría cuestionar seriamente la concepción rawlsiana de justicia.

El segundo eje del argumento de Lizárraga se halla en la diferencia entre tolerancia y overlapping consensus (consenso traslapado). La 
tolerancia es anterior y secundaria, mientras el consenso traslapado constituye el elemento en que Rawls verdaderamente ha pensado para resolver conflictos entre valores. Cuando las personas edifican la concepción política de la justicia desde el interior de sus propias convicciones morales, religiosas y políticas se alcanza el consenso traslapado. Esto permite reconocer un importante punto de coincidencia entre Lizárraga y Montero: que la concepción de justicia de Rawls de ningún modo puede resolver dilemas morales individuales o anular convicciones éticas particulares. Por ser una concepción política de la justicia, es una continuación de las concepciones particulares de las personas. Son estas las que brindan razones para aceptarla. En síntesis, la objeción de Lizárraga se resume en que los principios de justicia son políticos, no morales, y he allí la novedad de la teoría de Rawls.

Finalmente, en el último de los comentarios, Graciela Vidiella se concentra en la reconstrucción del liberalismo a la que apeló González. Para ella la tolerancia es recalcitrante o irrelevante solo porque González de la Vega ha reconstruido el liberalismo de acuerdo a las premisas que describen los sistemas normativos jurídicos. Mientras que, por el contrario, entenderlo como un sistema moral nos llevaría a otra conclusión: no siempre es un esquema de principios completo y consistente, lo que deja espacio suficiente para inconsistencias y dilemas. Si esto es así, la aludida incoherencia entre liberalismo deontológico y tolerancia no es plausible. Y por otro lado, esto también embiste contra la plausibilidad de la existencia de verdaderos dilemas de la tolerancia cuando se trata de conflictos de valores morales en el esquema liberal.

Una idea detrás del argumento de Vidiella es el reconocimiento de la tolerancia como una virtud que se ejercita practicándola y que requiere de una especial sensibilidad moral en el agente. Con ello la autora está reclamando un mayor papel para la virtud en toda teoría moral. En este punto, parece compartir la preocupación de Fernando Lizárraga y René González de la Vega de que algunas concepciones legalistas sobre la moralidad pueden decantar en meros procesos de depuración de principios más que en verdaderas guías de acción para el agente. Y es en esa posibilidad donde deberíamos poner un alerta. 
La discusión cierra con un comentario de René González de la Vega quien, aun concediendo razón a algunas de las objeciones que le han señalado, insiste en que el problema "profundo" que significa el ejercicio de la tolerancia en el ámbito privado subsiste. Es decir, persiste el problema que se genera en la persona cuando surge la contradicción entre principios morales; y persiste justamente porque adoptamos todos los presupuestos que el liberalismo deontológico supone. Para reforzar sus argumentos, elabora una respuesta contextual que pone en evidencia la tensión que le preocupa y ya ha manifestado en su primer artículo: la aludida tensión entre el ejercicio circunstancial y particularizado que requiere la tolerancia, y las premisas esencialmente universalistas del liberalismo deontológico.

La discusión que han emprendido los cuatro autores tiene numerosas ventajas. Son artículos de un excelente nivel argumentativo y rigor teórico. El resultado es sumamente completo y enriquecedor. Tanto que en algún punto sirve de guía para estudiar los pasos teóricos que da el liberalismo político desde la autonomía individual hacia una concepción de la justicia. Sin duda, también resalta la vigencia e importancia del aporte de Rawls a la filosofía política.

Otro importante rasgo de la discusión es que nos lleva a pensar, en primera persona, el compromiso y espacio que estamos dispuestos a ceder a la tolerancia si consideramos las consecuencias prácticas que conlleva. ¿Es la tolerancia una actitud pasajera que adoptamos circunstancialmente o constituye un principio de vida arraigado en el conjunto de nuestras convicciones morales? ¿Es la pérdida moral que implica la tolerancia una señal de que debemos preferir otra salida liberal a un conflicto de valores, o es apenas una de las exigencias que posibilitan el desarrollo de los múltiples planes de vida de los ciudadanos libres e iguales en nuestras sociedades modernas? Y finalmente, este intercambio de razones nos llama la atención sobre algunos presupuestos del liberalismo deontológico que reconocemos como aquellos principios que todo liberal está dispuesto a defender. 